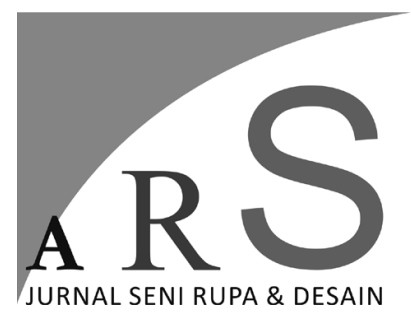

Volume 23 Nomor 1 Januari - Maret 2020

\section{SENI LUKIS SURYALISME KARYA SENIMAN KOEBOE SARAWAN SEBAGAI MEDIA REFLEKSI DAN EDUKASI TERHADAP MASYARAKAT}

\author{
Lucky Childa Pratama, Warih Handayaningrum \\ Program Studi Pendidikan Seni Budaya \\ Pascasarjana, Universitas Negeri Surabaya \\ E-mail : luckyc.pratama@gmail.com
}

\begin{abstract}
ABSTRAK
Dalam penelitian ini penulis memberikan informasi dan edukasi betapa pentingnya sebuah pembelajaran akan makna dan simbol dari sebuah visual atau lukisan, dari sini penulis berkeinginan untuk membahas jauh lebih dalam untuk mengidentifikasi lukisan seorang seniman Jawa Timur yaitu Koeboe Sarawan dengan aliran yang digeluti yaitu seni lukis suryalisme. Tujuan penelitian ini untuk mendeskripsikan bagaimana seni lukis beraliran suryalisme menjadi sebuah daya refleksi dan media pembelajaran dan manfaat bagi apresiasi penikmat seni. Dari fenomena tersebut penulis dapat mengkaji lewat pendekatan deskriptif dan penjabaran apa makna dan isi filosofi dengan menggunakan ilmu estetika dan seni rupa terhadap lukisan seorang seniman Koeboe Sarawan
\end{abstract}

Kata Kunci : lukis Suryalisme, refleksi, edukasi, masyarakat

\begin{abstract}
Painting Art Suryalism Works Of Artawan Koeboe Articles As A Media Of Reflection And Education Of The Community. In this study the author provides information and education on the importance of learning about the meanings and symbols of a visual or literary, from which the author wishes to discuss more deeply to identify the paintings of an East Javanese artist, Koeboe Sarawan, with the flow of suryalism. The purpose of which is to describe how painting in suryalism becomes a reflection and learning media and benefits for the appreciation of art lovers. from this phenomenon the author can examine through a descriptive approach and elaboration of what the meaning and content of philosophy using aesthetics and fine art by the painting of an Koeboe Sarawan artist
\end{abstract}

Keywords : art of Suryalism, reflection, education, society 


\section{Pendahuluan}

Perkembangan seni lukis banyak mengalami kemajuan, seiring dengan perkembangan teknologi yang digunakan sebagai media pendukung dalam penelitian tentang penciptaan karya seni lukis. Seni salah satu sifatnya adalah kreatif, bagi seorang pelukis ada kemungkinan terus melakukan berbagai eksperimen atau proses kreatif untuk mencari dan menemukan bentuk-bentuk baru secara estetis didalamnya mengandung unsur filosofi, konsep, ide, gagasan dan latar belakang dalam penciptaan suatu karya seni lukis.

Sebagai salah satu cabang dari seni rupa, bahwa seni lukis merupakan karya seni yang popular dan menunjukan perkembangan yang paling pesat diantara cabang seni rupa lainya, begitu pula seni lukis merupakan titik tolak dari perkembangan seni lain. (Hamzah, 1984).

Dalam penciptaan karya seni tidak saja pertanggungjawaban visual semata, tetapi memiliki kedalaman makna yang terkandung di dalamnya. Dalam hal ini Franz Boas menunjuk adanya dua dampak artistik sebuah karya, yaitu: (1) Kesempurnaan bentuk yang diperlihatkan melalui perlakuan teknik sehingga mencapai standar keunggulan tertentu, sehingga kesempurnaan bentuk berkaitan dengan keunggulan teknik; (2) Gagasan-gagasan yang diasosiasikan dengan bentuk dengan prinsip simbolisme, yaitu ketika sensasi dirangsang bukan oleh bentuk saja, tetapi juga melalui asosiasi antara bentuk dan gagasan yang dimiliki seseorang. Jadi, bentuk menyampaikan makna tertentu (Boas dalam Yustiono, 2004:10).

Sebuah gaya karakteristik oleh seniman Koeboe Sarawan yang memang cukup memberikan kesan yang mendalam dan penuh arti dalam setiap karyanya. Dalam penelitian ini penulis ingin membahas tentang makna dan isi lukisan seniman Koeboe Sarawan. mungkin juga akan membahas tentang sebuah makna. Penulis tertarik dengan pembahasan ini karena mungkin menurutnya seniman Koeboe Sarawan mempunyai gaya dan aliran yang cukup memberikan kesan pada penikmat seni. Penalaran pada konsepsi sebuah kehidupan ia tuangkan pada sebuah kanvas yang bertajuk lukisan menjadi karya yang sangat mempesona dan cukup bisa diperbincangkan.
Dalam ruang lingkup masyarakat sejatinya karya seni yang paling dimengerti oleh masyarakat pad umumnya adalah karya seni lukis, krena mungkin pada daarnya karya seni lukis adalah karya seni yang klasik yang tertua dari berbagai macam karya seni lainya, tetapi sayangnya memang pemaknaan atas seni lukis sendiri sekarang sudah sangat rendah dan sangat tertinggal dari pandangan masyrakat pada umunya. Seni lukis sendiri sudah sangat jauh meninggalkan pemahaman masyrakat yng sedangkan masyrakat masih memahami seni lukis yang berbau romantisme. Pemahamanpemahaman yang senjang ini coba penulis simpulkan sebagai media wacana bagaimana masyrakat memahami seni lukis terkini dengan media aliran seni lukis suryalisme.

Sebuah gaya karakteristik oleh seniman Koeboe Sarawan yang memang cukup memberikan kesan yang mendalam dan penuh arti dalam setiap karyanya. Dalam penelitian ini penulis ingin membahas tentang gaya karakteristik seniman Koeboe Sarawan pada karya karya kususnya pada lukisannya. mungkin juga akan membahas tentang sebuah makna . Penulis tertarik dengan pembahasan ini karena mungkin menurutnya seniman Koeboe Sarawan mempunyai gaya dan aliran yang cukup memberikan kesan pada sang penikmat. Penalaran pada konsepsi sebuah kehidupan ia tuangkan pada sebuah kanvas yang bertajuk lukisan menjadi karya yang sangat mempesona dan cukup bisa diperbincangkan.

Beberapa aspek yang bisa membedakan dari isi yang dikandung dari lukisan suryalisme adalah dari aspek keilmuan estetika dan mendeskripsikan lewat narasi sebuah wacana yang dilakukan dengan lewat wawancara terhadap seniman.

Antara estetika dan seni memiliki hubungan yang sangat kuat dan tidak bisa terpisahkan. Hal ini disebakan adanya satu kesatuan antara estetika dan karya seni yang sangat bermakna dan sangat berkonsep yang mendasar. Dalam hal ini akan memunculkan sebuah konsep yang bisa disebut the beauty dan the ugly. The beauty adalah sesuatu karya yang memang diakui banyak pihak yang memang memiliki kualitas standart keindahan, sedangkan The ugly adalah suatu karya yang sama sekali biasanya dinilai 
buruk namun jika dipandang dari banyak hal ternyata memperlihatkan keindahan

Menurut Soedarso,"Trilogi Seni" (2006:2) Seni adalah realisasidari usaha manusia untuk menciptakan hal-hal yang indah itu. Maka hal itu dapat disubstitusi dengan seni artinya bisa juga dikatakan bahwa seni adalah kebutuhan manusia yang terakhir sesuatu yang diinginkan setelah kebutuhan-kebutuhan yang inti terpenuhi seperti makan, minum, pakaian perumahan dan sejenisnya terpenuhi. Orang tidak akan mati atau menderita apabila tidak memanfaatkan dan menghasilkan seni, tetapi kalau ada mereka akan membuat atau mencarinya, walaupun bentuk dan jenis seni itu sendiri berlainan bentuknya.

Dari berbagai statement diatas seni lukis salah satu potensi dimana sebuah budaya penting yang memang harus dipahami dan dimaknai kalayak masyarakat pada umunya. Mengenai berbagai apa yang bisa disimpulkan oleh seniman terhadap karyanya adalah bukti sebuah catatan sejarah, bagaimana peran seni terhadap kelangsungan hidup dunia. Dari permasalahan dan pembicaran atau fenomena yang terjadi diatas maka penelitian ini bermaksud untuk memberikan gambaran tentang bagaimana karya seni lukis suryalisme memberikan penjelasan secara kongkrit dengan menggunakan media diskripsi untuk pengungkapanya agar menjadi bahan refleksi dan renungan pembelajaran pada masyarakat.

\section{Metode Penelitian}

Pendekatan ini menggunakan metode deskriptif yaitu mendesriptifkan ap a yang digagas oleh seniman Koeboe Sarawan terhadap karyanya agar dapat dijadikan media refleksi atau pembelajaran secara mendasar apa itu karya seni lukis beraliran suryalisme. Dan pada metode ini pendekatan menggunakan pembedahan dengan beberapa objek kajian yaitu ditinjau dari segi estetika dengan seni rupa, maka hasil simpulan bisa ditemukan.

Data yang diambil untuk penelitian ini adalah data yang langsung didapat dari sumber atau objek narasumber untuk selanjutnya dijadikan bahan untuk media refleksi atau pembelajaran oleh masyarakat. Data tersebut langsung diperoleh dari proses wawancara terhadap seniman yang menjabarkan isi $\mathrm{dn}$ konsepsi yang dipaparkan dalam bentuk lukisan, penulis memberikan sejumlah pertanyaan yang kaitanya dari beberapa aspek keilmuan untuk membeda karya dari seniman Koeboe Sarawan.

\section{Pembahasan \\ Metode Kajian Seni Rupa}

Hasil dari kajian dari senirupa meliputi beberapa aspek yaitu bentuk dan warna. Karena pada dasarnya unsur yang terkait pada pola terjadinya seni rupa meliputi bentuk dan warna.

\section{Kajian Seni Rupa Bentuk Dan Warna}

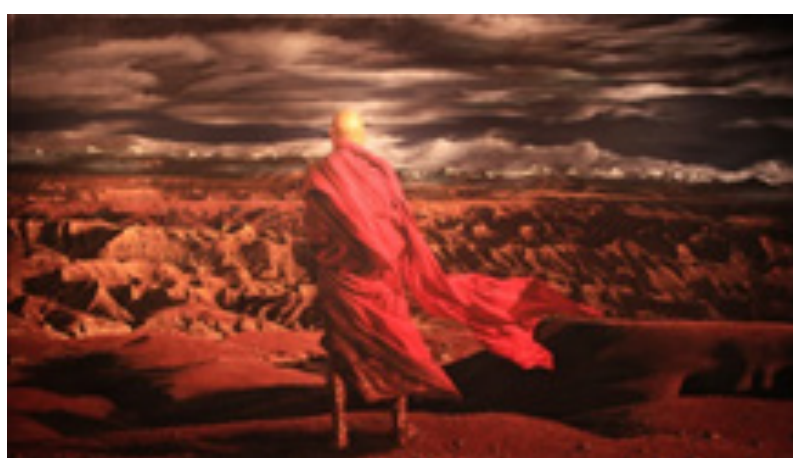

Gambar: "Puncak Keheningan"

(Sumber Foto Dok. Koeboe Sarawan 2017)

Puncak dari sebuah pemikiran, batin, dan jasmani menyentuh dalam sebuah alam hingga membumi seperti terpijak dan membatu. Bentuk figur yang terpampang pada lukisan adalah seorang biksu memakai jubah merah menghadap membelakangi, yang melatarkan sebuah padang pasir yang hampa tanpa adadanya tanda-tanda kehidupan.

warna merah pada jubah yang dipakai oleh figur pada lukisan ini menjelaskan ketegasan dan menjadi identitas yang dipakai, warna yang menggelayut pada nuansa horizontal latar berwarna redup dan gelap menegaskan bahwa keheningan yang tercipta pada alam yang nyata

Hasil dari unsur yang terkait pada kajian seni rupa menjelaskan bahwa lukisan yang berjudul "Puncak Keheningan" meberikan penjelasan yakni bahwa sebuah biksu buda memaknai unsur kerohanian, religious dan terkesan kepada hakekat hidup, dengan warna yang dominan gelap dan sayup memberi kesan mistik, misterius dan menegaskan kebijakan, dan ketegasan dibalik warna merah berselimut jubah. Dengan dasar pemahaman bahwa semua ada waktu dimana titik puncak dalam sebuah perenungan. 


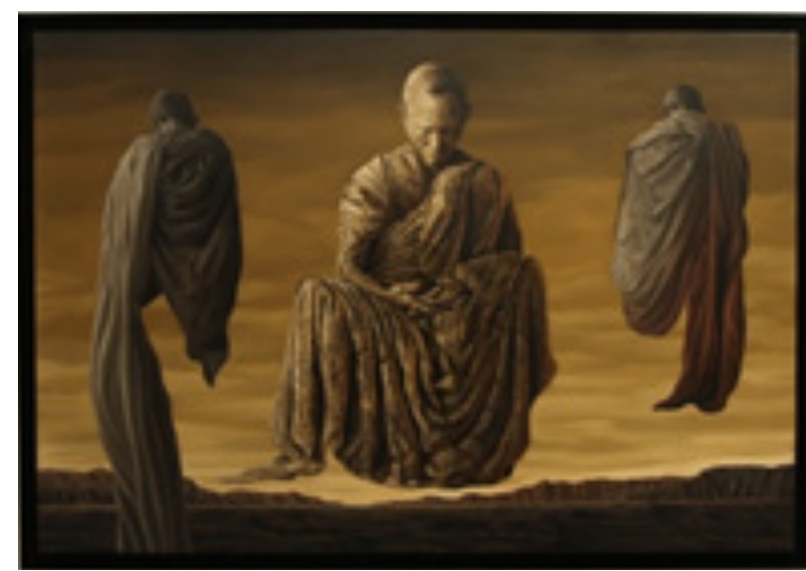

Gambar: "Pinacle Of Silence"

(Sumber: Foto Dok. Koeboe Sarawan 2017)

Karena manusia tercipta dari tanah dan akan kembali ketanah, dengan rohaninya manusia bisa mengontrol jasmani. Pada dasarnya kita berasal duniawi maka tak sadar kalau kita akan juga kembali ke bumi.

Bentuk yang digambarkan dalam figur lukisan adalah tiga orang biksu berjuba dengan keadaan membatu posisi duduk bersila keadaan mata tertutup, dan melayang tak menyentuh tanah.

Warna yang dipakai pada lukisan yang berjudul "Pinacle Of Silence" terkesan sayup berwarna kuning kehitaman, dengan nuansa hangat yang terpancar. Warna figur batu yang kusam akan keadaan alam.

Hasil analisis dari berbagai prinsip keseni rupaan memeparkan hasil bahwa bentuk yang digambarkan dalam figure seorang yang memakai jubah dengan keadaan membatu memberikan makna bahwa kekusukan atau kefokusan yang sangat puncak menghasilkan sebuah baktiar dan mencapai hasil tingkat tertinggi tak tergoyahkan, tak tergoda dengan hal apapun semacam hal duniawi, warna nuansa hangat memberi persepsi atau anggapan untuk lebih kearah ketenangan, mengontrol jiwa dan batin untuk lebih tenang dan hening.

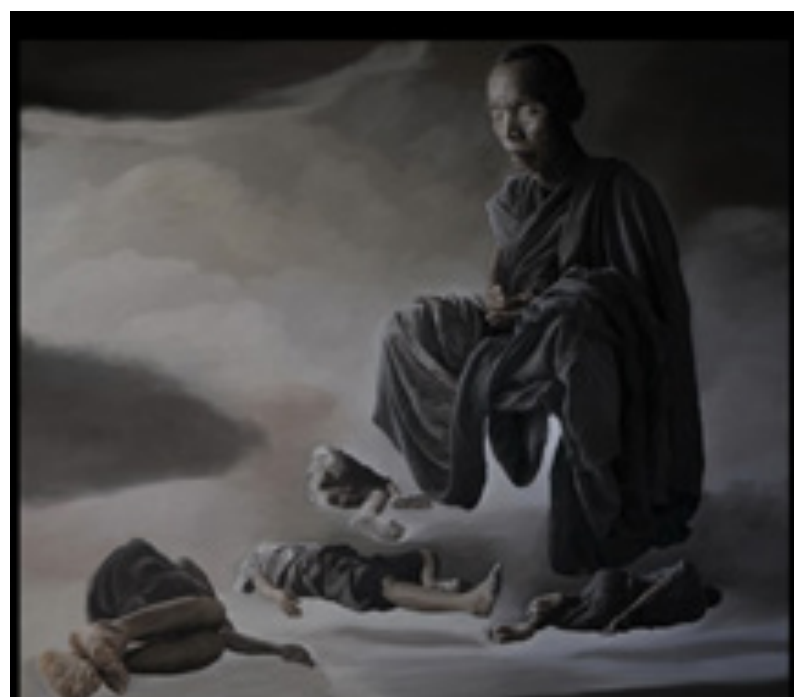

Gambar: “Menuju Cakrawala Baru \#2) (Sumber: Foto Dok. Koeboe Sarawan. 2017)

Tentang proses perenungan dan pendekatan terhadap tuhan, dan juga tentang spirit akan kita mengenal tuhan. Bentuk yang dipakai pada lukisan adalah figure seseorang bapak tua yang memakai jubah dengan keadaan duduk bersilah melayang tanpa menyentuh tanah, dengan keadaan mata terpejam, figur-figur yang lain disekitar nya adalah orang-orang tergeletak tak berdaya. Diantara nuansa sayup menghening diatas awan mengehanyut

Warna yang dipakai oleh lukisan adalah warna dominan menghitam dengan jubah menghitam dengan sayup berawan putih tebal. Menegaskan bahwa keterpurukan. Hasil analisis dari berbagai prinsip keseni rupaan memaparkan hasil bahwa bentuk yang digambarkan dalam figure orang tua yang sedang memakai jubah itu sedang memerhatikan pola tindakan beberapa aktivitas orang yang tergambarkan memaknai bahwa ada rasa dimana kegelisahan tiap seseorang dalam menjalani kehidupan, dengan warna yang cenderung gelap kehitaman akan sedikit beranggapan bahwa sedikit ada arah ke kematian dan kesedihan yang akan menghinggapi. 


\section{Metode Kajian Estetika}

Kajian Estetika Wujud, Bobot dan
Penampilan

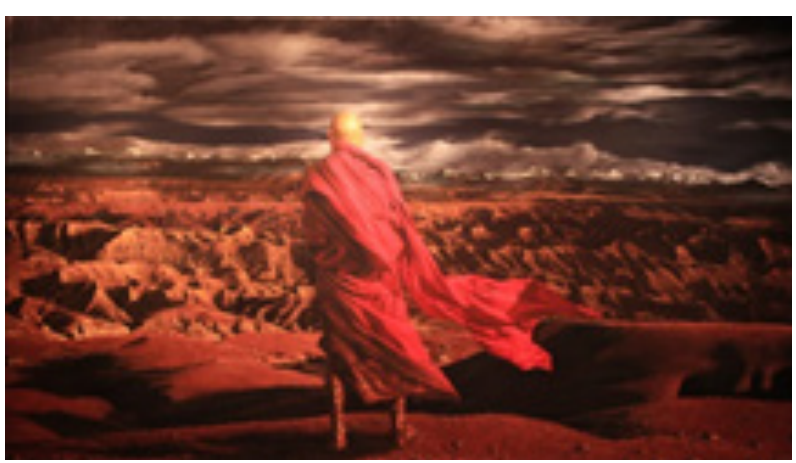

Gambar: "Puncak Keheningan"

(Sumber Foto Dok. Koeboe Sarawan 2017)

Dari wujud Terdapat figur orang mengenakan juba dan berambut gundul (biksu) yang menghadap membelakangi ditempat padang pasir yang bercuaca sayup senja. Dari bobot menyimpulkan puncak dari sebuah pemikiran, batin, dan jasmani menyentuh dalam sebuah alam hingga membumi seperti terpijak dan membatu. Skill yang digunakan dalam teknik melukis adalah teknik realis dikombinasikan dengan unsur surealis. Memakai nuansa horizon yang memaparkan keadaan alam yang mengelanyut dibalik senja

Dari ketiga unsur estetika yang memaparkan berbagai penjelasan tentang lukisan bisa dilihat, bahwa lukisan Koeboe Sarwan yang berjudul "Puncak Keheningan" mempunyai arti puncak dari segalah keusikan didunia dari batin yang menduniawi sampai titik yang teratas, dari penggambaranya memakai figure biksu buda Nampak membelakangi dan menatap hamparan pasir yangterlihat kosong, seolah-olah berada dititik puncak dalam sebuah keadaan.

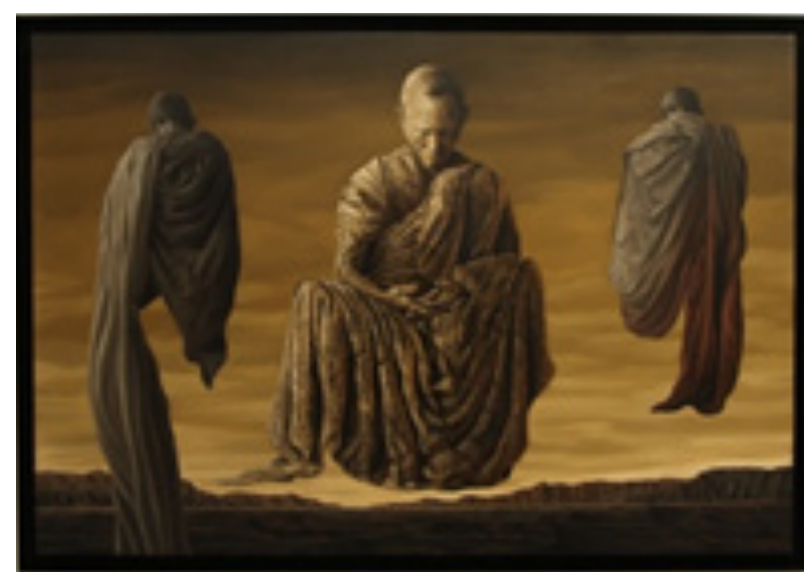

Gambar: "Pinacle Of Silence" (Sumber: Foto Dok. Koeboe Sarawan 2017)
Terdapat figure tiga orang biksu yang dua menghadap membelakangi dan berbentuk semacam membatu. Karena manusia tercipta dari tanah dan akan kembali ketanah, dengan rohaninya manusia bisa mengontrol jasmani. Pada dasarnya kita berasal duniawi maka tak sadar kalau kita akan juga kembali ke bumi. Mempunyai unsur penyajian sebagai teknik yang menimbulkan kesan detail dan rumit proses penggarapanya, terlihat nyata dan penuh penguasaan konsep tinggi.

Pemaparan dari ketiga unsur estetika mejelaskan, manusia tercipta hanya untuk sementara dan akan kembali dimana asalnya berada, kesan tekstur batu pada tubuh manusia mengaskan pada akhir difinal akan kembali lagi ditanah asal kita berada.

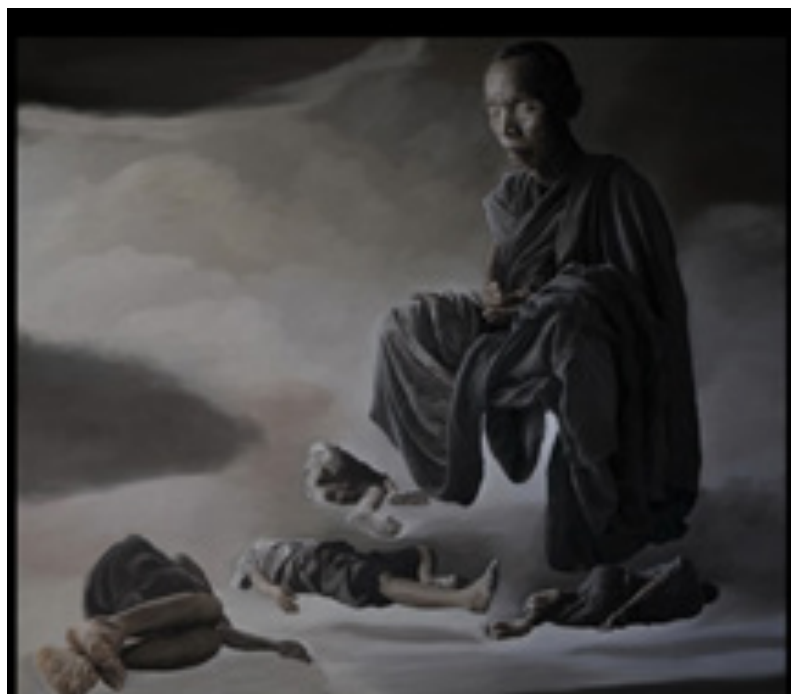

Gambar: “Menuju Cakrawala Baru \#2)

(Sumber: Foto Dok. Koeboe Sarawan. 2017)

Terdapat figure seorang kakek tua yang memakai juba lusut sedang duduk bersila melayang, disekitarnya terdapat orang-orang tergeletak dan tak berdaya. Tentang proses perenungan dan pendekatan terhadap tuhan, dan juga tentang spirit akan kita mengenal tuhan. Terlihatunsuryangditampilkan adalah penguasaan dan penghayatan sehingga memunculkan kesan manusia yang relative proporsi.

Dari ketiga unsur estetika memaparkan penjelasan bahwa ada kekuatan dimana saat kita kembali lagi ke sang pencipta, mendapatkan kembali rasa dimana kita mempunyai spirit.

\section{Kesimpulan}

Berdasarkan uraian hasil peneletian pada penulisan ini, maka penulis bisa menyimpulkan 
bahwa dalam setiap karya lukisan Koeboe Sarawan yang diambil oleh penulis mengenai tema keheningan sering memunculkan obyek diantaranya adalah bentuk atau figur biksu, bentuk figur manusia, bentuk batu, figure jubah, kayu, dan nuansa alam lembah pasir yang luas, dan awan yang sering membungkus setiap jenis lukisanya. Serta pemakaian warna dalam setiap lukisan Koeboe Sarawan cenderung sering menampilkan warna-warna yang terkesan gelap dari pada warna-warna yang terang. Komposisi antara latar yang dibuat lebih kearah nuansa alam lembah pasir dan tanpa ada tanda-tanda kehidupan disekelilingnya.

Proses terjadinya sebuah karakter yang dibuat Koeboe Sarawan yang memakai segalah macam bentuk figure manusia berjubah adalah bukan tidak mungkin dari perjalananya selama Ia berkunjung di Tibet, negeri dimana Koboe mendapat pengalaman masalah kerohanian dan spiritual religious, selama ia disana setiap waktu Koeboe selalu dipertontonkan barisan biksu yang sedang melakukan perjalanan dengan mengenakan jubah warna merah dengan ciri khasnya. Disitulah Koeboe terasa sangat terkesan dengan hal-hal yang ada disana, merespon memunculkan segala karakter yang terbuat sekarang.

Pemaknaan yang bisa diambil dari pole pembelajaran dan pengertian dari hasil lukisan suryalisme yang dihadirkan oleh seniman Koeboe Sarawan adalah tetap menggunakan unsure pengalaman dalam memaknai lukisan suryalisme. Masyarakat atau publik bisa memaknai apa arti dari lukisan adalah interaksi seniman lewat pola pemaknan pengalaman.

\section{Daftar Pustaka}

Dharsono (Sony Kartika), Hj. Suarmi. (2007). Estetika Seni Rupa Nusantara. Surakarta: ISI Press Solo.

R. Semiawan, Conny. (2010), Mitodologi Penelitian kualitatif. Jakarta: PT. Gramedia Widiasarana Indonesia.

Iwan acep, (2008), Narasi simbolik seni rupa kontemporer Indonesia. Isac Book Arts And Culture.

Sp., Soedarso. (2006). Trilogi Seni: Penciptadn, Eksistensi, dan Kegunaan Seni. Yogyakarta: Badan Penerbit Institut Seni Indonesia Yogyakarta

Sutrisno Mudji. (1999). Kisi-kisi Estetika, Yogyakarta: Penerbit Kanisius. 